\title{
Meeting Report: USP Workshop on Topical and Transdermal Drug Products
}

Margareth Marques

e-mail:mrm@usp.org

United States Pharmacopeia, Rockville, MD

$\mathrm{T}$

he U.S. Pharmacopeia (USP) is developing two new general chapters for topical and transdermal drug products: $<3>$ Topical and Transdermal Drug

Products_Product Quality Tests and $<725>$ Topical and Transdermal Drug Products-Product Performance Tests. The proposals for these two general chapters were published in Pharmacopeial Forum 35 (3), pages 602-611 and pages 615-626, respectively. The general chapter $<3>$ contains the procedures for tests such as viscosity, tube (content) uniformity, and adhesion. The procedures for drug-release tests for semi-solid topical dosage forms using the vertical diffusion cell are discussed in general chapter $\langle 725\rangle$. These two new general chapters were developed by the USP Advisory Panel on Topical and Transdermal Performance Tests (see photo). A workshop to discuss the comments received on these proposals was held at USP headquarters in Rockville, MD, on September 14-15, 2009. About 80 experts on this topic participated in the discussions. Among the presentations made were the perspectives from the Consumer Healthcare Products Association (by Dr. Elliott, GlaxoSmithKline), the Generic Pharmaceutical Association (by Mr. Anderson, Nycomed, and Mr. Hougton, Mylan Pharmaceuticals), and the Food and Drug Administration (by Dr. Paul Schwartz). The slides of the presentations made at the workshop are available at www.usp.org/goto/topical. All comments and suggestions received during the public comment period and at the workshop will be considered, and new versions of the general chapters, with the inclusion of the approved comments, will be published in an issue of Pharmacopeial Forum during the first half of 2010. For more information, please contact Dr. Margareth Marques at MRM@usp.org.

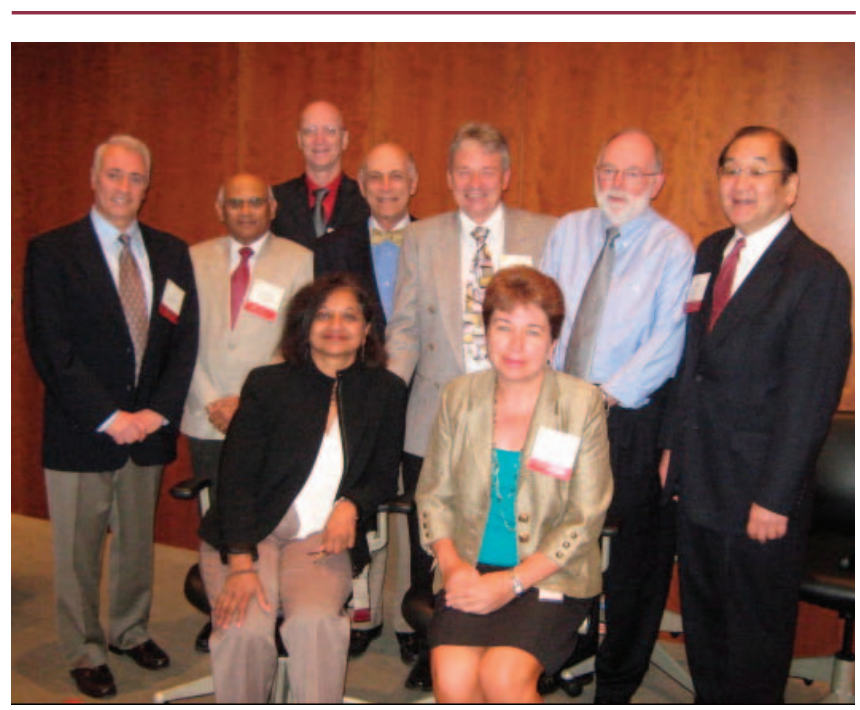

USP Advisory Panel on Topical and Transdermal Performance Tests. Back row, from left to right: Dr. Avi Yacobi (Taro Pharmaceuticals, Canada); Dr. Vinod Shah (consultant); Dr. Gary Ewing (Schering-Plough); Dr. Howard Maibach (University of California at San Francisco) ; Dr. Kris Derdzinski (Johnson \& Johnson); Dr. Gordon Flynn (College of Pharmacy, University of Michigan); Dr. Clarence Ueda (College of Pharmacy, University of Nebraska). Front row, from left to right: Dr. Kailas Thakker (Analytical Solutions Inc., USA); Dr. Margareth Marques (USP). Members not in the picture: Dr. Steve Shaw (Hanson Research) and Dr. Howard Rytting (deceased). 